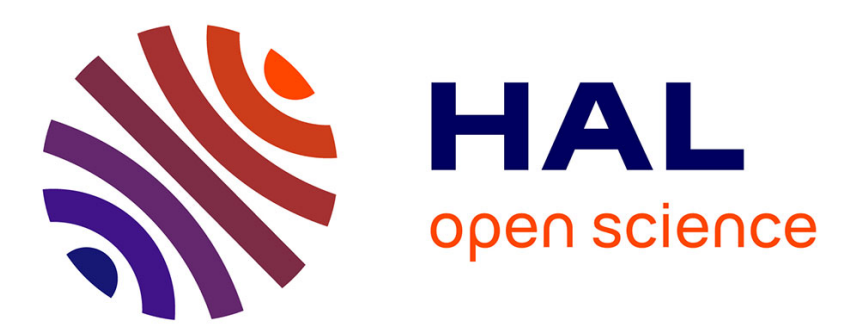

\title{
Performances of flax shive-based lightweight composites with rapid hardening
}

\author{
V Dubois, A Leblanc, O Carpentier, G Alhaik, E Wirquin
}

\section{To cite this version:}

V Dubois, A Leblanc, O Carpentier, G Alhaik, E Wirquin. Performances of flax shive-based lightweight composites with rapid hardening. Construction and Building Materials, 2018. hal-03285010

\section{HAL Id: hal-03285010 https://hal.science/hal-03285010}

Submitted on 13 Jul 2021

HAL is a multi-disciplinary open access archive for the deposit and dissemination of scientific research documents, whether they are published or not. The documents may come from teaching and research institutions in France or abroad, or from public or private research centers.
L'archive ouverte pluridisciplinaire HAL, est destinée au dépôt et à la diffusion de documents scientifiques de niveau recherche, publiés ou non, émanant des établissements d'enseignement et de recherche français ou étrangers, des laboratoires publics ou privés. 


\title{
Performances of flax shive-based lightweight composites with rapid hardening
}

\author{
V. Dubois*, A. Leblanc, O. Carpentier, G. Alhaik, E. Wirquin \\ Univ. Artois, EA 4515, Laboratoire de Génie Civil et géo-Environnement (LGCgE), \\ F-62400 Béthune, France
}

\begin{abstract}
This research work aims to develop a rapid hardening lightweight composite including flax shives, foaming agent and earthern materials. The results show a satisfying workability just after the mixing step and a rapid hardening of about less than thirty minutes. The mixes with a large amount of flax shives show a thermal conductivity inferior to $0.1 \mathrm{~W} \cdot \mathrm{m}^{-1} \cdot \mathrm{K}^{-1}$ and porouslike acoustic absorption coefficients. Even if the mechanical performances are low $\left(f c_{28 \text { days }}=0.1-1 \mathrm{MPa}\right)$, the developed mixes, in association with a structural material, can be used with advantage the 3D printing technique.

Keywords: Foam composite, Rapid hardening, Insulating materials, 3D printing.
\end{abstract}

\section{Introduction}

Growing in the field of construction, 3D printing consists of joining materials layer upon layer to obtain part or all of a building from a 3D model developed by CAD software. The 3D printing allows the building of various shapes. By significantly reducing useful matter to build, 3D printing allows to optimize resources [1][2]. This technique is the subject of several pieces

\footnotetext{
*Corresponding author
Preprint submitted to Construction and Building Materials. Dubois) December 22, 2017
} 
of research including the development of printing materials such as concrete, metal or earth. In most current applications, the printed material serves as the structural part of bearing walls [3][4][5]. But, to bring thermal or acoustic comfort to the user, a wall must also have insulating performance, which is given by insulating materials. In most common 3D printing projects, these materials are not included during the process.

In conventional techniques, lightweight concretes have been developed both

so to meet varying levels of mechanical strengths as well as to simultaneously provide thermal and acoustic performances. Lightweight concretes can be obtained by including lightweight aggregates and/or foaming agents. Lightweight aggregates can be natural (e.g. pumice, volcanic cinder) or artificial (e.g. expanded perlite, polystyrene, fly ash cenospheres or aerogel) [6] [7] while foaming agents are surfactant molecules that entrap air voids in the solid components during the mixing. In its fresh state, foam concrete must have a stable consistency to avoid segregation observed with insufficient foaming agent content or collapse due to the lack of aggregates to entrap [6].

At hardened state, the performances of lightweight concretes are variable according to their composition, the fabrication mode and their density. Table 1 shows characteristics of foam concretes with various densities. Several pieces of research work show the link between compressive strength and density. Liu et al. [8] have studied lightweight concrete containing perlite aggregate and the results have shown that the compressive strength is a 45 function of oven-dry bulk density according to a power law. Horpibulsuk et al. [9] have developed an empirical relation between unconfined compressive strength and void/cement ratio. The intrinsic porosity of lightweight ag- 
gregates and/or the pores generated by foam agents also induce interesting thermal and acoustic performances by reducing heat transfer and by increasing absorbing sound. Testing various surfactants, Samson et al. [10] show that the thermal conductivity varies linearly with the dry density regardless of the surfactant employed, with values similar to autoclaved cellular concrete (Table 1). As regards acoustics, Hung et al. [11] show that the sound absorption of foams increases as its relative density decreases. With a density of $400 \mathrm{~kg} \cdot \mathrm{m}^{-3}$, the acoustic absorption coefficient of their materials is between 0,48 and 0,9 for a frequency interval of $100-5000 \mathrm{~Hz}$, with transmission losses between 16 and $42 \mathrm{~dB}$.

\section{Table 1}

Performances of foam concretes

\begin{tabular}{|c|c|c|c|c|}
\hline Type of concretes & References & $\begin{array}{c}\text { Range of } f_{c} \\
(\mathrm{MPa})\end{array}$ & $\begin{array}{c}\text { Range of } \lambda \\
\left(\mathrm{W} \cdot \mathrm{m}^{-1} \cdot \mathrm{K}^{-1}\right)\end{array}$ & $\begin{array}{l}\text { Range of density } \\
\left(\mathrm{kg} \cdot \mathrm{m}^{-3}\right)\end{array}$ \\
\hline $\begin{array}{l}\text { Foam concrete including expandable } \\
\text { polystyrene, Portland cement or alumi- } \\
\text { nate cement, silice fume, polypropylene } \\
\text { fibers, foaming agent }\end{array}$ & {$[6]$} & $3-13$ & $0.09-0.25$ & $400-800$ \\
\hline $\begin{array}{l}\text { Lightweight cementitious composite in- } \\
\text { corporating aerogels and fly ash ceno- } \\
\text { spheres }\end{array}$ & {$[7]$} & $17-24$ & $0.32-0.41$ & $1000-1300$ \\
\hline $\begin{array}{l}\text { Shotcrete including cement, sand and } \\
\text { expandable perlite }\end{array}$ & {$[8]$} & $2-4.6$ & $0.1-1.44$ & $620-2080$ \\
\hline $\begin{array}{l}\text { Foam including gypsum, cement, su- } \\
\text { perplasticizer and surfactant }\end{array}$ & [10] & $0.03-5.03$ & $0.08-0.2$ & $247-819$ \\
\hline $\begin{array}{l}\text { Lightweight concrete without foaming } \\
\text { agent and including expandable perlite }\end{array}$ & {$[12]$} & $0.1-1.1$ & $0.13-0.21$ & $392-673$ \\
\hline Autoclaved cellular concrete & {$[13]$} & $2-4.6$ & $0.08-0.2$ & $300-500$ \\
\hline
\end{tabular}

In addition to performances, foam concretes are interesting from an environ- 
mental point of view because of the low amount of aggregates required for a given volume in comparison to conventional concretes, which allows to preserve natural resources. However, cement, which is a traditional component in the mix design of foam concrete, needs large quantity of energy to be manufactured. When the requested mechanical performances are low, cement can be replaced by lime, gypsum or natural prompt cement, for example, which are generated at lower temperatures than ordinary cement. Besides, gypsum and natural prompt cement offer a rapid setting to the material which can be interesting for the 3D printing.

To accentuate further the "green side" of a building product, clay earth can also be chosen as a binder such as in the traditional earthen buildings. This 70 is a mineral resource that can come from to the building site, therefore not requiring transportation. Besides, its energy requirements remain limited. Two-thirds of the worldwide population live in homes made with unfired earth such as compressed earth bricks or adobe bricks. Considering only the manufacturing phase, Maskell et al. [14] explain, relying on the ICE and Ecoinvent databases, that the choice of unfired extruded clay brick induces an embodied energy saving of $86 \%$ compared to fired clay and of $25 \%$ compared to concrete blocks. The $\mathrm{CO}_{2}$ emissions decrease, respectively, by $86 \%$ and $72 \%$. Furthermore, the grey energy of earth plaster is considered around $30 \mathrm{kWh} \cdot \mathrm{m}^{-3}$ while those of gypsum plaster and cement plaster are around, respectively $750 \mathrm{kWh} \cdot \mathrm{m}^{-3}$ and $1100 \mathrm{kWh} \cdot \mathrm{m}^{-3}$. One disadvantage of unfired earth techniques is the long drying time.

In order to further decrease the environmental impact of concrete, another solution derived from eco-construction techniques is the use as aggregates of 
vegetable co-products (e.g. straw), which are renewable materials and offer interesting thermal and acoustic behaviour whether on their own or combined with unfired earth materials (e.g. cob) thanks to their multi-scale porosity. Dubois et al. [15] have manufactured and tested blocks containing earthern materials, lime and hemp straw. Some of those blocks have thermal and acoustic performances which are better than the traditional gypsum block. However, from a mechanical point of view, the use of vegetable coproducts in the design of concretes generally induces a decreasing of strengths. Vercelheze et al. [16] have thereby designed baked foams including sugarcane fibres and show that fibres not only decrease the density but also the strength at failure and increase the deformation level. Treatments of vegetable coproducts are developed and improve their mechanical performances. Thus, Khazma et al. [17] show treatments using linseed oil for flax-shives cementitious composites which multiply the compressive strengths by ten and the flexural strengths by six to eight in comparison to composites without treatment of flax shives. By allowing the use of locally available and inexpensive materials, earth materials and vegetable co-products have a decisive role to play in the development of 3D printing applied to the building sector. Russel [18] demonstrates the great potential of earth materials to be an innovative solution to the housing shortage the developing world is facing. Some examples of the use of earth materials in 3D printing have been developed in Italy with the WASP project or also the ICAA project Pylos in Spain.

In this context, this research work aims to develop a lightweight composite with insulating performances and including eco-materials, for the 3D printing in the building domain. This composite has to be used in addition to 
structural material. In a fresh state, a satisfying workability and a rapid

The gypsum $(G)$ used in this research work is known as plaster of Paris. This plaster is mainly compounded of beta hemihydrate $\left(\mathrm{CaSO}_{4}, 1 / 2 \mathrm{H}_{2} \mathrm{O}\right)$ 
and anhydrite $\left(\mathrm{CaSO}_{4}\right)$. The natural prompt cement $(\mathrm{PC})$ is siliceous cement, formed between 800 and $1200^{\circ} \mathrm{C}$, including di-calcium silicate, calcium aluminate rich in alumina and calcium sulfoaluminate.

The quarry fines $(Q F)$ include limestone $(\sim 62 \%)$, kaolinite $(\sim 12 \%)$, illite $(\sim 7 \%)$, quartz $(\sim 11 \%)$, goethite $(\sim 3 \%)$ and dolomite $(\sim 5 \%)$. The size of the particles ranges from 0.1 and $100 \mu \mathrm{m}$. The quarry fines are defined as Ap (low plastic clay) according to the USCS classification with a plastic index of $11 \%$ and a liquid limit of $33 \%$ measured by application of the NF P 94-051 standard [19]. Flax shives $(F S)$ have variable sizes inferior to 40 $\mathrm{mm}$ (Fig. 1). The bulk density is around $105 \mathrm{~kg} \cdot \mathrm{m}^{-3}$. In general, straw is known to have a high porosity and its porosity induces large and fast water absorption, which, in our case can be seen (Fig. 1) with a water absorption of $130 \%$ (mass ratio water/dry straw) thirty seconds after immersion.

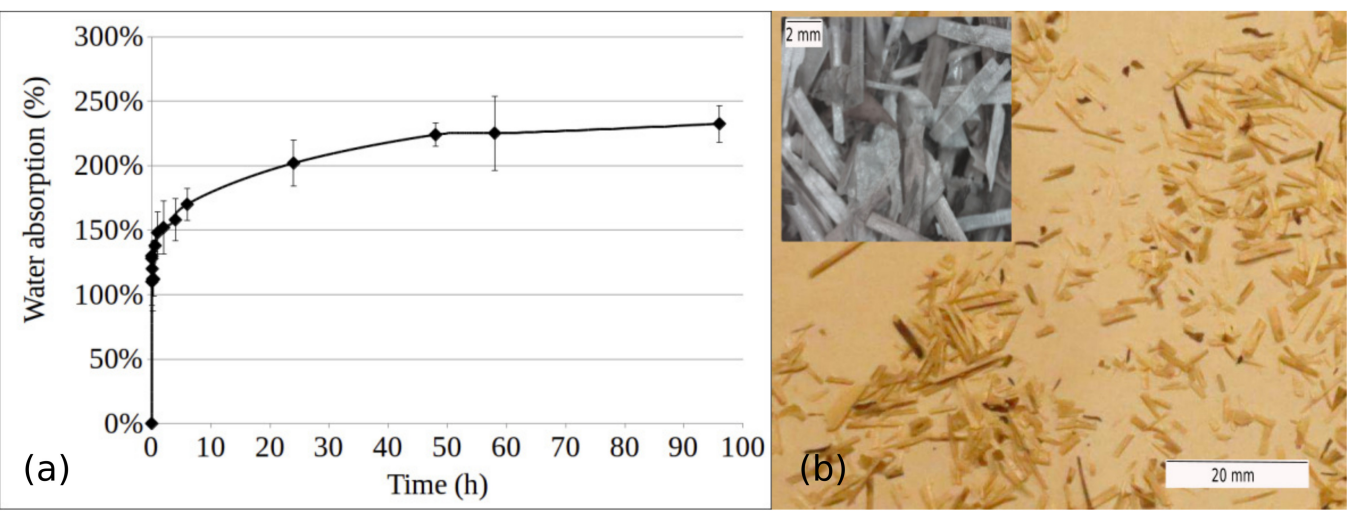

Fig. 1. Flax shives a) Water absorption coefficient according to time b) Photo including microscope view

The foam agent chosen in this study is a liquid additive for concrete and mortar, including sodium lauryl ether sulphate as tensioactive molecule. 


\subsection{Mix design}

The mix design is based on the binder/aggregate ratio $(\mathrm{B} / \mathrm{A})$, the water/binder ratio $(\mathrm{W} / \mathrm{B})$, the foaming agent / binder ratio $(\mathrm{FA} / \mathrm{B})$. These ratios are weight ratios. The term binder corresponds to the gypsum, the Prompt cement, and quarry fines. The term aggregate corresponds to flax shives. In this paper, the mixes are referenced with a series of numbers after letters ( $\mathrm{G}, \mathrm{PC}$ and $\mathrm{QF}$ ) indicating the binder, the two first numerals being the $\mathrm{W} / \mathrm{B}$ ratio without decimal point and the following numerals, the $\mathrm{B} / \mathrm{A}$ ratio.

FA is added in the designation of the mix whenever the foaming agent is in the composition. The foaming agent content is fixed with a FA/B of $0.7 \%$. $\mathrm{FA}+$ means that $\mathrm{FA} / \mathrm{B}$ is increased to $1.6 \%$ instead of $0.7 \%$. Four types of binders are studied: $100 \%$ G, $50 \%$ G $+50 \%$ QF, $100 \%$ PC, $50 \%$ PC $+50 \%$ QF. With QF, two other percentages are studied with gypsum and prompt cement (table 2): $25 \% \mathrm{QF}+75 \% \mathrm{G}$ or PC $; 75 \% \mathrm{QF}+25 \% \mathrm{G}$ or PC. Among all those mixes, four of them are considered as references: G1, G-QF1, PC1, PC-QF-1 which have a B/A of 10 and a FA/B of $0.7 \%$. The water content 65 is chosen to have a sufficiently fluid mix for a correct filling while allowing a rapid hardening. To satisfy these criteria, the workability has been evaluated by a flow table test. The flow table test is a method to determine the consistency of fresh mortars. This method is used to select the suitable water content necessary to obtain a constant spreading of each mixture according to the NF EN 1015-3 French standard [20]. However, with gypsum and natural prompt cement, the consistency of mixes changes quickly. In order to compare the mixes, the reference spreading diameter is measured five minutes 
after the incorporation of water in the mixer. For each mix, measurements are carried out according to three directions and an average is calculated to state. 


\subsection{Methods}

\subsubsection{Workability and hardening}

After mixing, the fresh behaviour is studied up to the hardening of the materials. In this aim, several flow table tests are done with the same mix until the measure becomes stable. Each spreading diameter is measured after the application of 15 shocks [20]. A measure is considered as stable when the diameter reaches $100 \mathrm{~mm}$. Simultaneously, a Vicat test is carried out. When the distance between the needle and the base plate reached $4.0 \mathrm{~mm}$, the measured time will be the initial setting time for the mix [21]. This setting time is compared to the time necessary to have a stable measurement with the flow table.

\subsubsection{Samples tested at hardened state - Curing period}

Various samples have been prepared to do mechanical, acoustic and thermal tests. During the preparation, the material is not vibrated. Consistency is similar to a self-compacting concrete. In this case, vibration could lead the foam to collapse. Samples are kept in their mould until their hardening, then are unmolded and are stored in a climatic room, which maintains the controlled atmosphere at $20^{\circ} \mathrm{C}$ and a relative humidity of $50 \%$.

The mechanical performances have been measured by compressive tests on cylindrical samples, with a diameter of $110 \mathrm{~mm}$ and a height of $220 \mathrm{~mm}$. The tests are done after four curing times (just after the start of setting then 3, 14 and 28 days). Two cylindrical samples have been prepared for the three first curing periods and three cylinders for 28 days. For acoustic tests, cylindric samples, with a diameter of $100 \mathrm{~mm}$ and a height of $100 \mathrm{~mm}$, are prepared and stored for 28 days. For the thermal tests, parallelepiped blocks of 250 
$\mathrm{mm} \times 250 \mathrm{~mm} \times 80 \mathrm{~mm}$ are manufactured and stored 28 days.

At the end of the curing period, the dimensions of the samples are measured.

225 [22] in their research works on hemp concrete to avoid to obtain incorrect values due to bad distribution of the load inside the samples. 


\subsubsection{Acoustic absorption measurements}

The acoustic measurements are conducted following the E2611-09 ASTM standard [23]. Based on a transfer matrix approach, this method requires an impedance tube (10 cm diameter), four microphones, and a digital frequency analysis (Fig. 2).
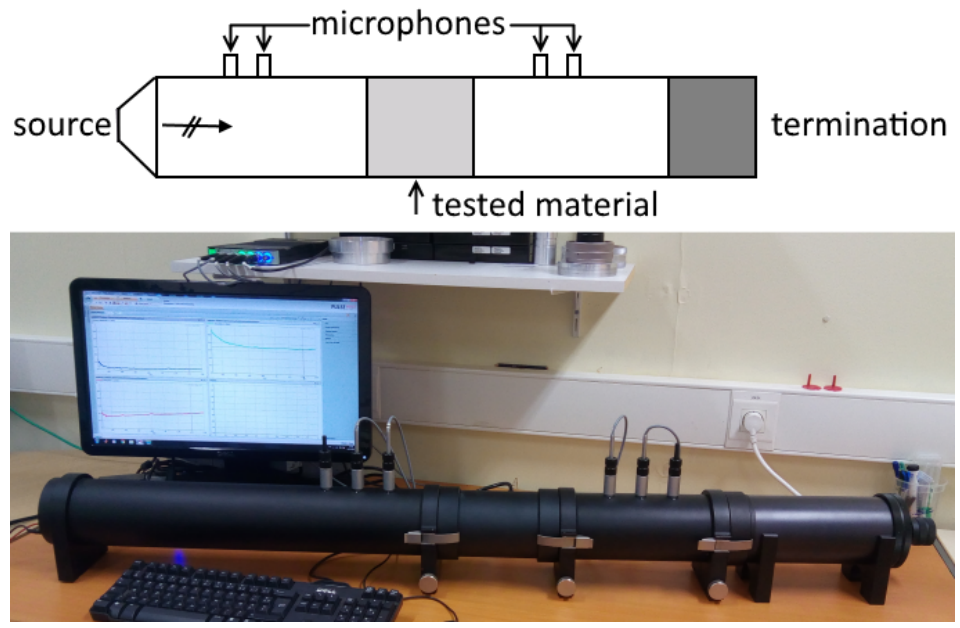

Fig. 2. Acoustic measurement configuration

Two-load measurements are performed on each cylindrical samples of the tested materials, first with the tube termination open, and then with the downstream tube sections terminated by a large amount $(\geq 50 \mathrm{~cm})$ of sound absorbing material. Using this method allows us to distinguish the fraction of the incident energy that is effectively dissipated within the sample. Thereby, the absorption coefficient determined here is an anechoic dissipation coefficient defined as:

$$
\alpha=1-\left|R_{a}\right|^{2}-\left|T_{a}\right|^{2}
$$


$R_{a}$ and $T_{a}$ are the normal incidence, respectively plane wave reflection and transmission coefficients. Thus, $\alpha$ measures the difference between the fraction of the incident energy absorbed by the material at its front surface and transmitted to its rear surface.

260

\subsubsection{Thermal study}

The thermal properties of the samples (thermal conductivity $\lambda$ and their specific heat capacity $C_{p}$ ) are determined based on standard NF EN 12664 [24]. The method consists in simultaneously measuring temperatures and heat flow on both faces of the sample. Surface temperatures are measured by

265 T-type thermocouples and heat flows are measured by fluxmeters (150 x 150 $\mathrm{mm}^{2}$ sensors with a sensibility of $100 \mu \mathrm{V} \cdot \mathrm{W}^{-1} \cdot \mathrm{m}^{-2}$ by Captec). Temperatures are imposed on both sides of the sample thanks to two exchanger plates. Flow temperature inside the exchangers is controlled by bath thermostats (accuracy of thermal regulation : $0.05{ }^{\circ} \mathrm{C}$ ). The sample and flow meters assembly is surrounded by an insulating belt to ensure unidirectional flow in the central measurement area. To determine $\lambda$, a temperature gradient is generated $\left(\Delta T=10^{\circ} \mathrm{C}\right)$ and $\lambda$ is calculated for a difference of heat flow close to zero on both sides of the sample. The test apparatus used in this study is presented in Fig. 3. The thermal conductivity is then expressed by the following formula:

$$
\lambda=e \frac{\sum \varphi}{2 \Delta T} \quad\left(\mathrm{~W} \cdot \mathrm{m}^{-1} \cdot \mathrm{K}^{-1}\right)
$$

with $e$ the measured thickness of the sample, $\sum \varphi$ the sum of both recorded heat flows at the surface of the sample and $\Delta T$ the temperature 
gradient.

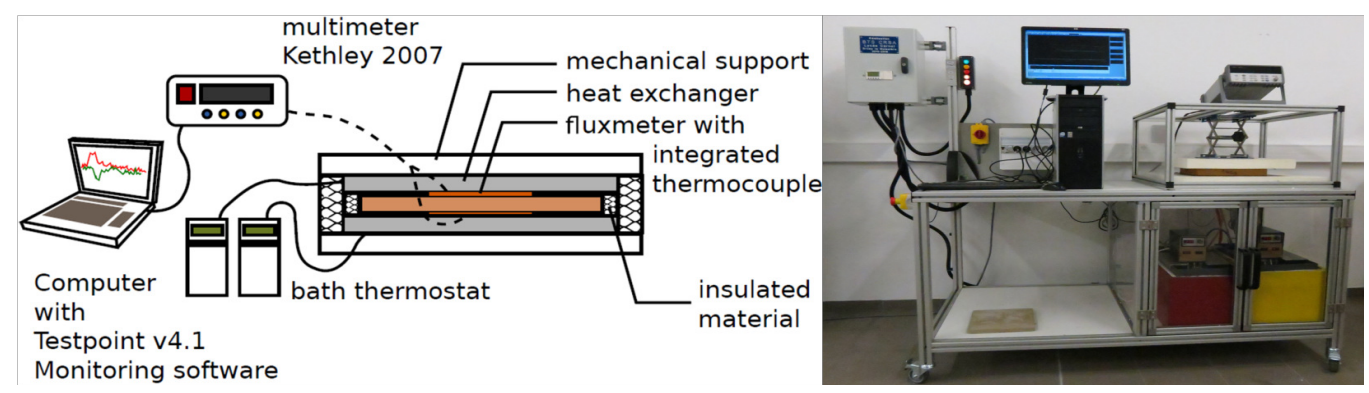

Fig. 3. Thermal measurement apparatus using the heat flow meter method

The calculation of the specific heat capacity of the sample needs to record all thermal data between an initial time and an ending time. At the initial state, the system must be isothermal $\left(T_{i n i}\right)$. Then the setpoints of the bath thermostats are changed to a higher temperature. The sample stores an amount of energy until thermal balance is reached. $C_{p}$ is expressed by the following formula:

$$
C_{p}=\frac{\int_{t \min }^{t \max } \Delta \varphi \cdot \mathrm{d} t}{T_{\text {end }}-T_{\text {ini }}} \cdot \frac{1}{\rho \cdot e} \quad\left(\mathrm{~J} \cdot \mathrm{kg}^{-1} \cdot \mathrm{K}^{-1}\right)
$$

with tmin and tmax the time recorded for the initial state and the time at the end of the test respectively, $\Delta \varphi$ the heat flow difference measured by fluxmeters at both side of the sample, $T_{\text {end }}$ and $T_{i n i}$ the mean measured surface temperature at $\operatorname{tmax}$ and $\operatorname{tmin}$ respectively and $\rho$ the density of the sample. Those measurements are performed and recorded every 5 seconds thanks to a Kethley 2007 Multimeter linked to a computer using the TestPoint v4.1 monitoring software.

An evaluation of the dynamic thermal behaviour of a modelled wall made of 
our materials is given.

295 


\section{Table 2}

Description of the mixes

\begin{tabular}{ccccc} 
& Mixes & \multicolumn{3}{c}{ Mass ratio } \\
Short Ref. & Long Ref. & W/B & B/A & FA/B \\
\hline G0 & G 08 10 & 0.8 & 10 & 0 \\
G1 & G 08 10 FA & 0.8 & 10 & $7 \times 10^{-3}$ \\
G2 & G 08 10 FA+ & 0.8 & 10 & $1.6 \times 10^{-2}$ \\
G3 & G 08 5 FA & 0.8 & 5 & $7 \times 10^{-3}$ \\
\hline G-QF0 & G QF 08 10 & 0.8 & 10 & 0 \\
G-QF1 & G QF 08 10 FA & 0.8 & 10 & $7 \times 10^{-3}$ \\
G-QF2 & g QF 08 10 FA & 0.8 & 10 & $7 \times 10^{-3}$ \\
G-QF2' & G qf 08 10 FA & 0.8 & 10 & $7 \times 10^{-3}$ \\
G-QF3 & G QF 08 5 FA & 0.8 & 5 & $7 \times 10^{-3}$ \\
\hline PC0 & PC 08 10 & 0.8 & 10 & 0 \\
PC1 & PC 08 10 FA & 0.8 & 10 & $7 \times 10^{-3}$ \\
PC2 & PC 08 10 FA+ & 0.8 & 10 & $1.6 \times 10^{-2}$ \\
PC3 & PC 08 5 FA & 0.8 & 5 & $7 \times 10^{-3}$ \\
\hline PC-QF0 & PC QF 08 10 & 0.8 & 10 & 0 \\
PC-QF1 & PC QF 08 10 FA & 0.8 & 10 & $7 \times 10^{-3}$ \\
PC-QF2 & pc QF 08 10 FA & 0.8 & 10 & $7 \times 10^{-3}$ \\
PC-QF2 & PC qf 08 10 FA & 0.8 & 10 & $7 \times 10^{-3}$ \\
PC-QF3 & PC QF 08 5 FA & 0.8 & 5 & $7 \times 10^{-3}$ \\
\hline
\end{tabular}




\section{Results and discussion}

In this part, the authors show the results of the study at fresh and hardened states, according to the tests previously described.

\subsection{Hardening kinetics}

300

The behaviour at fresh state is studied by flow table tests and Vicat tests. These tests aim to follow the evolution of matters from the mixing up to the hardening stage. Table 3 shows the mean spread diameter five minutes after water incorporation during mixing; the time to obtain stable spread diameter indicating the start of the hardening; and the initial setting time measured by Vicat test $\left(\mathrm{T}_{\text {Vicat }}\right)$. The time measurements start as soon as the water is introduced into the mixer. The spread diameter after five minutes gives the fluidity level just after the mixing step. The time corresponding to a spread diameter of $100 \mathrm{~mm} \pm 10 \mathrm{~mm}$ gives the time to reach to the higher level of thixotropy which can coincide with the start of the hardening process in the sense of the Vicat test. By comparing the mixes with and without foaming agents, the results show that the foaming agent increases the fluidity of the mixes and the time before the start of setting. When the measurement was possible, the results by Vicat test show that the time between the water-adding step during the mixing and the start of initial setting is below 33 minutes. In the table, some results for Vicat test are considered as immeasurable while the hardening of some materials was observed. For the mixes with $\mathrm{B} / \mathrm{A}=5$, the structure of the matter was very open due to the high presence of flax shives. The needle passed easily through the matter. This specific structure gives a "thixotropic" behaviour to the material 


\subsection{Dry density}

In following the procedure described in 2.4.1., the dry densities have been measured (Table 4). Among all the studied mixes, the dry densities vary from 386.9 up to $878.3 \mathrm{~kg} \cdot \mathrm{m}^{-3}$. 
The mixes with gypsum are lighter than the mixes with prompt cement. Without foam agent, the dry densities are around $780 \mathrm{~kg} \cdot \mathrm{m}^{-3}$ for mixes with gypsum and $880 \mathrm{~kg} \cdot \mathrm{m}^{-3}$ for mixes with prompt cement. With a substitution by quarry fines, the results are similar.

The percentage change in dry density gives interesting results concerning the influence of both the foam agent and the flax shives on the proportion of air voids. The comparison of the mixes without foam agent and the "reference" mixes (G1, G-QF1, PC1, PC-QF1) shows a decrease in dry density comprised between 19.3 and $31.2 \%$. A larger quantity of foam agent accentuates the decrease in dry density, in particular for $\mathrm{PC} 2$. The mixes with $\mathrm{B} / \mathrm{A}=5$ show a large decrease in their dry density due to the structural arrangement and the intrinsic porosity of flax shives [25].

Table 5 gives the proportions of each component for all the studied mixes, except G-QF2 and PC-QF2. The decrease in gypsum proportion or prompt cement proportion in mixes including foam agent is shown in the last column, in comparison with the mixes without foam agent and without quarry fines (G0 or PC0). The decrease can be very sharp with values from 17.6 up to $79.9 \%$. The decrease is sharper for mixes including quarry fines and foam agent, in particular for mixes having a $\mathrm{B} / \mathrm{A}$ ratio of 5 . This result can be interesting regarding both the reduction needs in terms of granular source and to promote short circuit for raw materials. Further studies could be carried out to verify results with others types of earth materials and straw.

\subsection{Compressive strengths}

Fig. 4 shows the compressive strengths of all the studied mixes, except G-QF2 and PC-QF2, after the four curing periods. Besides, for the mix PC- 
QF3, the mechanical tests have not been done because the samples were too weak and broke on demoulding.

Overall the results show that gypsum gives higher compressive strengths than prompt cement for similar composition. The partial replacement of hydraulic binder ( $\mathrm{G}$ or PC) by quarry fines and/or the addition of foam agent induce a 375 large decrease in compressive strength. By comparing the mixes with $100 \%$, $75 \%$ then $50 \%$ of gypsum or prompt cement, the higher the substitution rate is, the more the compressive strength decreases. The results of G1, G2 and PC1, PC2 show that a higher proportion of foaming agent does not seem to change the compressive strengths. With a higher proportion of flax shives, the flexural strengths decrease sharply except for the mix G3 containing gypsum as binder. The coating of particles with gypsum alone seems sufficient to maintain the level of resistance obtained with G1. For G-QF3, the partial replacement of gypsum by quarry fines decreases the quality of links between particles. Concerning the prompt cement, the known chemical incompatibility between straw (or wood) and ordinary Portland cement could explain the lower compressive strengths observed compared to those obtained with mixes containing gypsum. This chemical incompatibility due to the release of sugar by straw when in contact with water induces retarded settings and hardening. An improvement of resistance level could be considered, in a further study, by testing the treatment of flax shives as in the research work of Khazma et al. [17]. Besides, the choice of foaming agent inducing different values of resistance for the same composition of material [10]. Other foaming agents could be tested, as various foam content in mixes. 


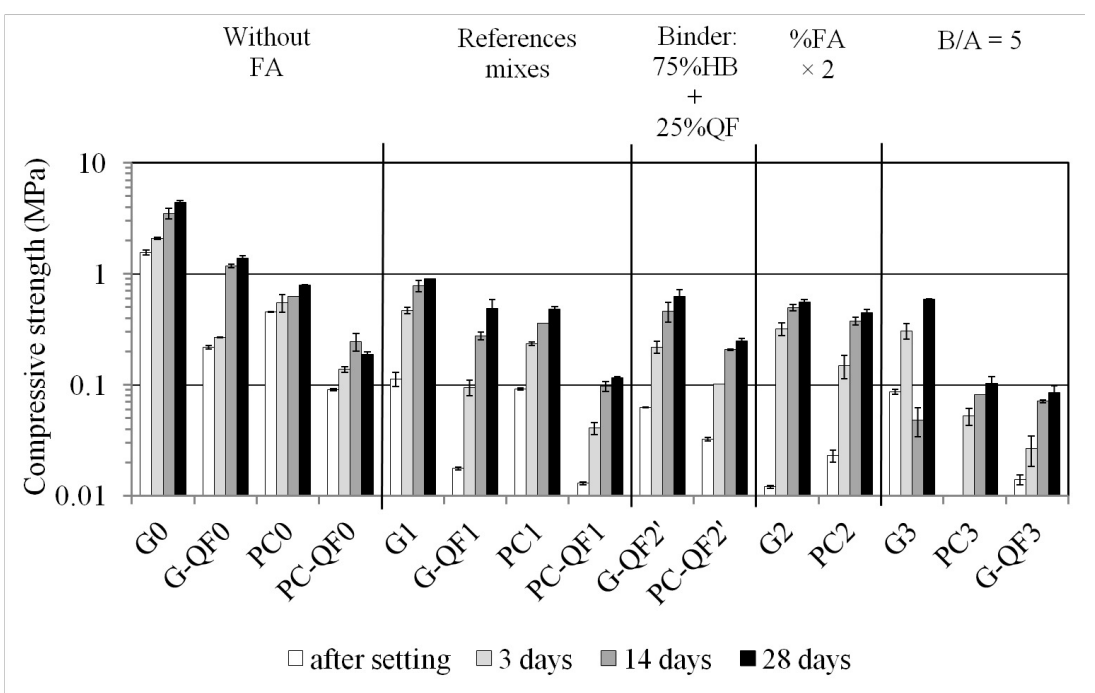

Fig. 4. Compressive strengths according to four curing periods

G2 is the mix with the lowest compressive strength just after setting. During the 3D printing of a wall, the bottom part of the wall will be able to resist its own weight up to a height of $2.4 \mathrm{~m}$. This height $\mathrm{H}$ was calculated with the equations below:

$$
\begin{aligned}
f_{c} & =\frac{m \cdot g}{S} \\
f_{c} & =\frac{\rho_{d} \cdot S \cdot H \cdot g}{S} \\
H & =\frac{f_{c}}{\rho_{d} \cdot g}
\end{aligned}
$$

With $f_{c}$, the compressive strength $(\mathrm{Pa}), m$ the mass of the wall, $\rho_{d}$ the 400 dry density $\left(\mathrm{kg} \cdot \mathrm{m}^{-3}\right), g$ the standard acceleration due to gravity considered equal to $9.81 \mathrm{~m} \cdot \mathrm{s}^{-2}$ and $\mathrm{S}$, the surface of loading.

By applying this formula with the other mixes, PC-QF1 gives the lowest 


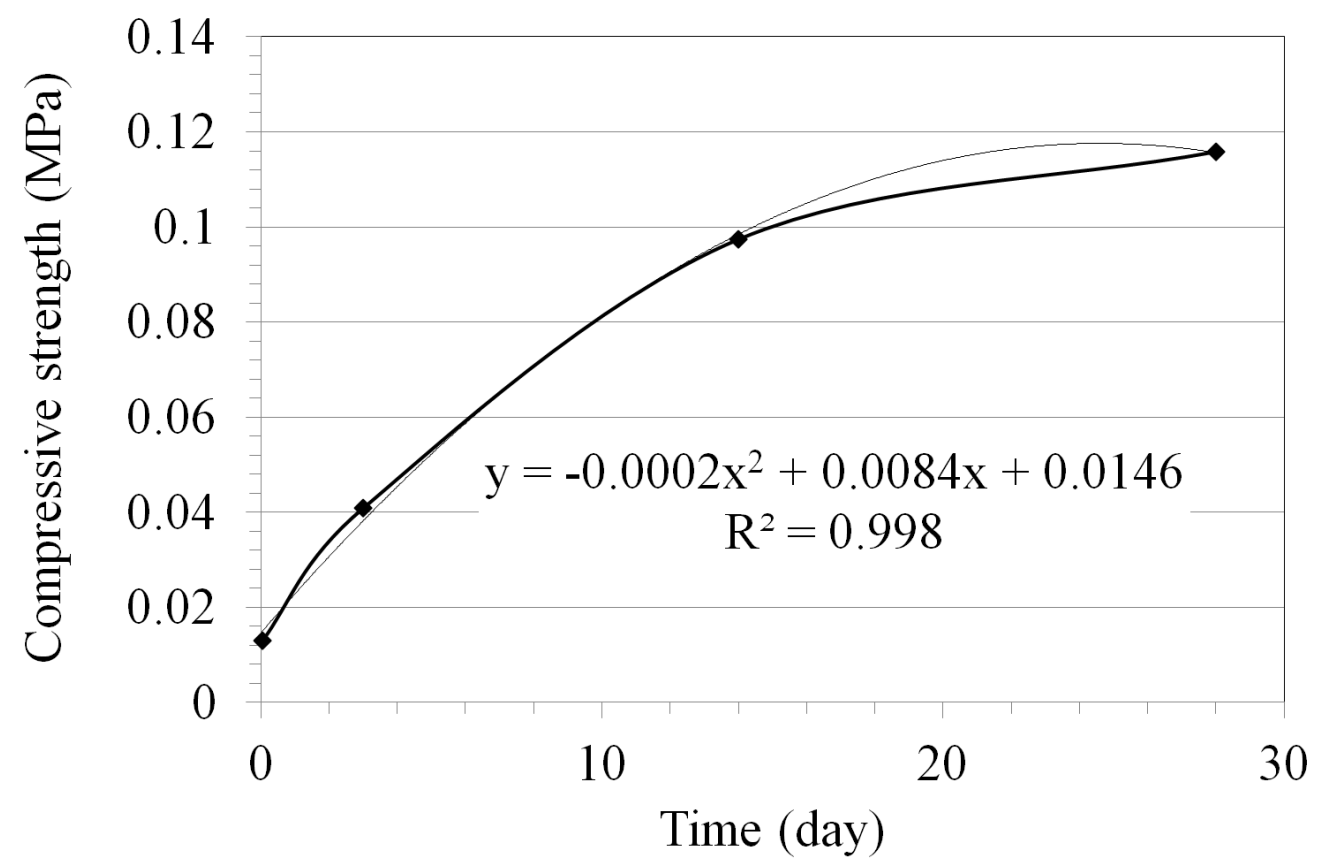

Fig. 5. Evolution of compressive strengths of PC-QF1 according to the curing periods

height with a value of $2 \mathrm{~m}$. Fig. 5 shows the evolution of strengths for PCQF1. By extrapolation, the compressive strength at 1 day can be estimated at $0.032 \mathrm{MPa}$, which allows to reach a height of $4.9 \mathrm{~m}$ before rupture. Belayachi et al. [26] have arrived at a similar conclusion about a mix compounded of straw and gypsum plaster, which had a binder/aggregate ratio of 5 and a high water/binder ratio $(\mathrm{W} / \mathrm{B}=1.1)$.

Fig. 6 shows the compressive stress according to the strain after setting 410 and at 3,14 and 28 days of curing, for two mixes representative of this study. The graphs show a similar behaviour to the results of Chen et Liu [6] with curves in three parts: 
- Part 1: the stress increases slowly with strain probably due to the collapse and the compaction of surface pores or defects

- Part 2: a linear increase of the strain with stress (elastic stage)

- Part 3: stabilization or light decrease of the stress while the strain increases.
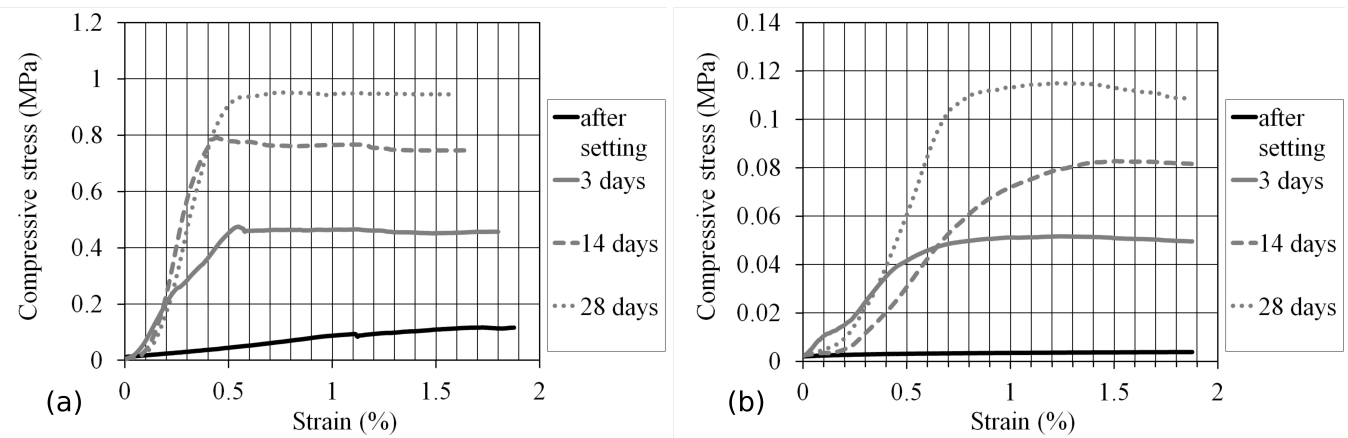

Fig. 6. Compressive stress vs strain at various curing time for a) G1 and b) PC3

All these results show that no studied mixes can be used as structural material. From the perspective of this study, a treatment of flax shives could be done to highly decrease water absorption capacity and the release of hydrosoluble molecules that could improve the mechanical performances of our mixes and allow to obtain a material with sufficient resistance to be a bearing material, such as the autoclaved aerated concrete.

\subsection{Acoustic absorption}

The mixes presented in Table 2 were evaluated using the procedure described in section 2.4.4. For the sake of clarity, acoustic absorption for 11 
formulations are shown in Fig. 7. Also, some results (as those of the PC-QF3) have been discarded because of the non-repeatability of the measurements, due to their difficulty of use (being particularly brittle) in the impedance tube.

For the basic formulations, a behaviour similar to conventional concretes is observed. The acoustic energy is almost entirely returned. Nevertheless, those mixes cannot be seen as homogeneous materials since only their density and thickness are the discriminating parameters. Here, incorporation of the quarry fines has a significant impact: while low, the acoustic absorption is doubled from G0 to G-QF0, and from PC0 to PC-QF0. Thus, acoustic behaviour can be seen as an intermediate between the absorption brought by the flax shives and the reflection caused by the binder (similar to hemp concrete [27]). More remarkably, and when a foaming agent is used, results show a change in acoustic behaviour. Mixes G3, G-QF3 and PC3 exhibit porous-like acoustic absorption coefficients. Thus, the porosity obtained by the addition of a foaming agent appears particularly judicious in the perspective of obtaining an acoustically effective building material. Mixes G1, G-QF1, PC1 and PC-QF1 have an intermediate acoustic behaviour in comparison to the two groups of mixes described above.

\subsection{Thermal properties}

The analysis of the thermophysical properties of our samples are summarised in Table 6. The results are compared to a hemp straw/earth block and an autoclaved aerated concrete (AAC) block, a commonly used material in building. Even if there is still room for improvement, earth block and alternative technologies for building can generally complement traditional 


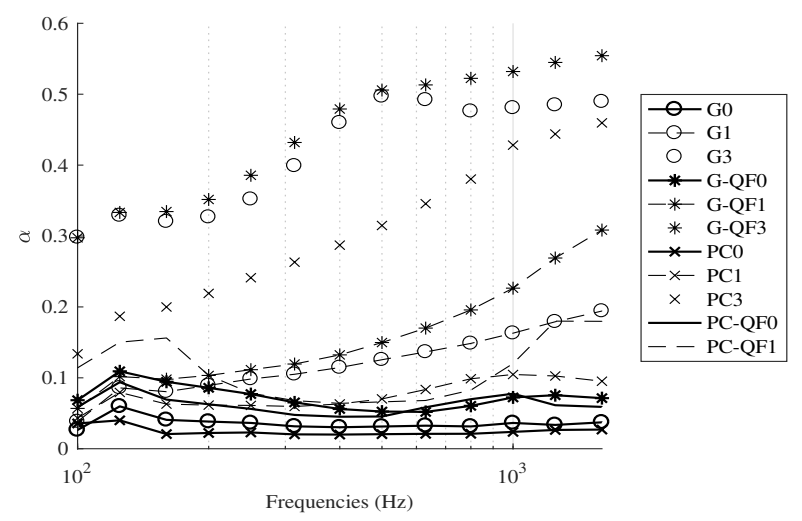

Fig. 7. Acoustic absorption for eleven representative elaborated mixes

materials in terms of thermal performances [28]. Indeed, a comparison of our formulations with AAC blocks shows thermal properties that are comparable in terms of heat capacity. Mixes G3 and G-QF3 are also close enough (about $12 \%$ higher) in terms of AAC thermal conductivity. PC-QF1 mixes complete with AAC thermophysical properties with a similar thermal conductivity. The comparison with the hemp straw/earth block shows a difference that is even greater as far as thermal performances are concerned. Results are clearly visible by comparing thermal conductivity but also for other thermophysical properties and especially for G3, PC3, G-QF3 and PC-QF1 mixes. As expected, the foaming agent induces a high porosity that encapsulates air inside the porous media and produces good earth-based insulator. This dependence between the density and the thermal conductivity of our mixes is clearly observed in Table 6 . Furthermore, the heat capacity of our mixes 465 is quite good in that it is similar to those of AAC blocks.

Knowing $\lambda, \rho$ and $C_{p}$, the thermal diffusivity $a$ and the thermal effusivity 
$b$ can be easily determined. These dynamic thermal characteristics are useful to study the thermal performances of building materials like time lag $t_{l}$ and decrement factor $d_{f}$. The time lag can be defined as the delay due to the thermal mass. A material with an important thermal time lag is able to better preserve the thermal environment inside a building against long periods of high or low external temperatures. The decrement factor represents the reduction in cyclical temperatures on the inside surface compared to the outside surface. A material with a low decrement factor also offers a protection against the influence of weather conditions by reducing the surface temperature amplitude inside a building.

There are numerous methods to determine $t_{l}$ and $d_{f}$ (analytical, numerical, experimental). In the specific case of sinusoidal variation of input thermal stress, such as those found in daily thermal variations, the time lag $t_{l}$ and the decrement factor $d_{f}$ at a given depth $e$ can be computed thanks to the following expression [29] :

$$
\begin{gathered}
T(x, t)=T_{m} \exp \left(-x \sqrt{\frac{\omega}{2 a}}\right) \cos \left(\omega t-x \sqrt{\frac{\omega}{2 a}}\right) \\
t_{l}=T(0, t)_{\max }-T(e, t)_{\max } \quad(\mathrm{h}) \\
d_{f}=\frac{T(e, t)_{\max }-T(e, t)_{\min }}{T(0, t)_{\max }-T(0, t)_{\min }}
\end{gathered}
$$

According to literature [30], a $240 \mathrm{~mm}$ depth material has a good thermal inertia for a time lag $t_{l}$ greater than $10 \mathrm{~h}$ and a decrement factor $d_{f}$ lower than 0.05. PC-QF1 mixes has a time lag of $15.96 \mathrm{~h}$ and a decrement factor 
of 0.0153 at $240 \mathrm{~mm}$ depth. These results make it suitable for implementation in building and a potential alternative insulation material, especially in lightweight wooden structure to compensate for their lack of thermal inertia. Concerning our mixes, PC-QF1 is the most promising insulation material.

\subsection{Porosity}

To better understand the results of acoustic and thermal tests, the porosity of some mixes has been observed.

At first, samples have been observed by microscope. Two types of structures have been seen: mainly opened porosity with mixes having the higher binder/aggregates ratio (G3, PC3, G-QF3, PC-QF3) and a no-connected porosity with the others mixes including foam agent. Fig. 8 shows the air voids obtained thanks to the foam agent (left - G3 and right - G1) and a high content of flax shives (left - G3). On the right-hand side of Fig. 8, the air voids are independent spherical bubbles of various sizes mainly inferior to $500 \mu \mathrm{m}$.
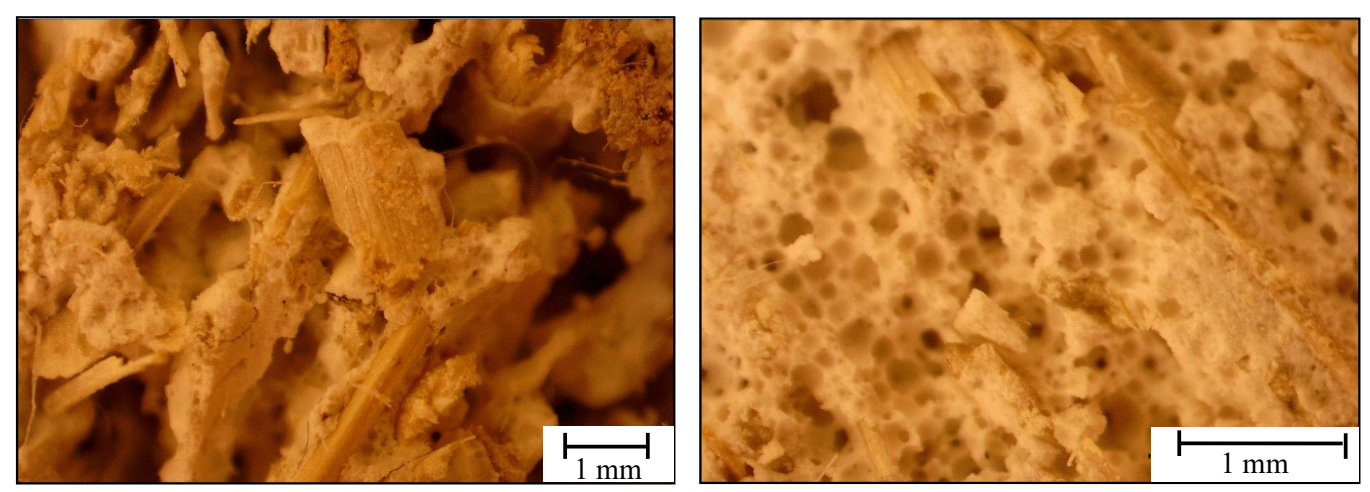

Fig. 8. Microscopic view of G3 (left) and G1 (right) 
To complete these investigations, CT-scan tests have been done on PCQF1 and G-QF3, which have respectively given the better results of thermal conductivity and acoustic absorption coefficient. The chosen computed tomography (CT) system is the XT H 225 ST (Nikon), suited to a wide range of materials and sample sizes. The tests have been done with the $225 \mathrm{kV}$ reflection target (focal spot size $3 \mu \mathrm{m}$ ) and the flat panel detector PE1621 (pixel size $200 \mu \mathrm{m}$ ). The data processing software was VG studio max 3.0. Fig. 9 shows the 3D images of void distribution for the two mixes (PC-QF1 and G-QF3). The blue colour indicates the presence of small volumes of air (inferior to $0.2 \mathrm{~mm}^{3}$ ) and the pink colour, the presence of large volumes of air or connected porosity. These tests confirm the observations under the microscope:

- With a high binder/aggregate ratio, the porosity is opened which gives a high acoustic absorption capacity. The thermal conductivity is low due to the combination of internal porosity of flax shives and the air bubbles generated by the foam agent

- The CT scan test of PC-QF1 shows a large proportion of independent small air volumes giving interesting thermal properties. The absence of opening in surface of the material induces a lack of acoustic absorption and a large part of returned acoustic energy.

\subsection{D printing test}

A 3D printing test has been performed to verify the adequacy between one of the developed composites and this building technique. The PC QF1 mix has been chosen for its better thermal performances. The tests aimed to 


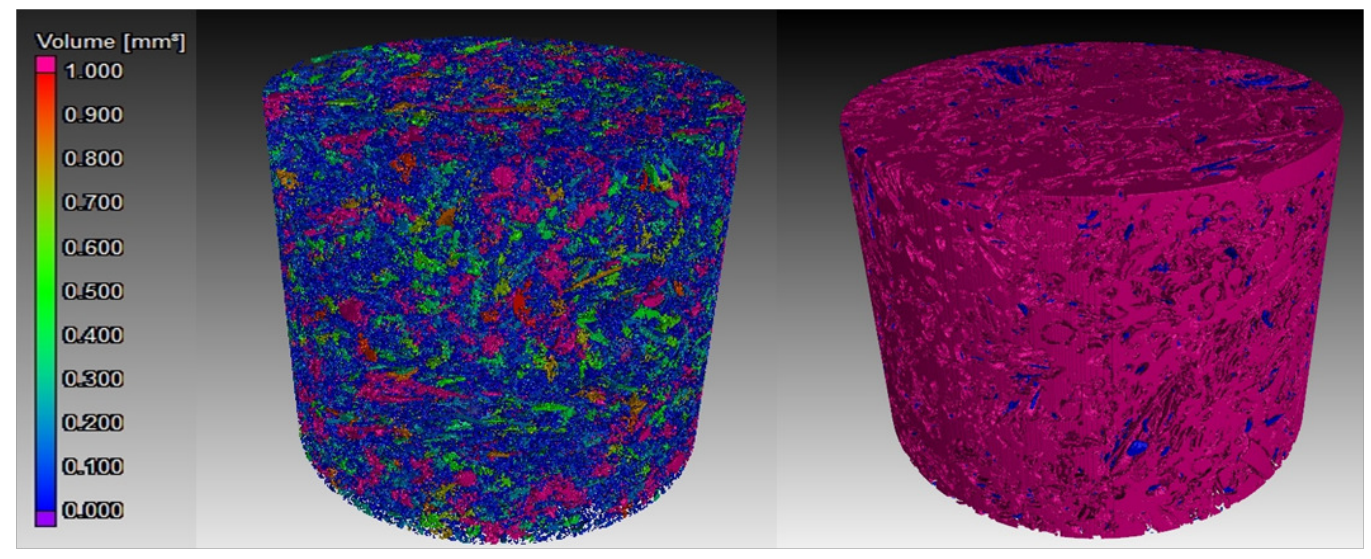

Fig. 9. CT-scan images of PC-QF1 (left) and G-QF3 (right)

fill a structure made in clayey materials. The structural material was printed 525 by a six axis manipulator that operates a nozzle (Fig. 10a and b)connected to a pipe for material deposit. The flow rate of material is ensured by a concrete pump.

The sides of the structure had a slight slope. A first test has been done without filling the structure. For a height of $21 \mathrm{~cm}$, the structure has crumbled ${ }_{530}$ (Fig. 10c) due to its own mass, the slope of the structure and the absence of internal support (zigzag) traditionally used in 3D printing. On the bottom right of the Fig. 10c, the form without filling is observable with two of its sides joined due to the collapsing.

A new test has been completed ; the structure has been filled with PC-QF1 every $15 \mathrm{~cm}$. After filling, the printing of structural material restarted. During the following printing phases of structural material, the PC-QF1 mix hardened and acted as a support to the structural material (Fig. 10c). The printing reached $55 \mathrm{~cm}$ without collapse of the element. This height was the 

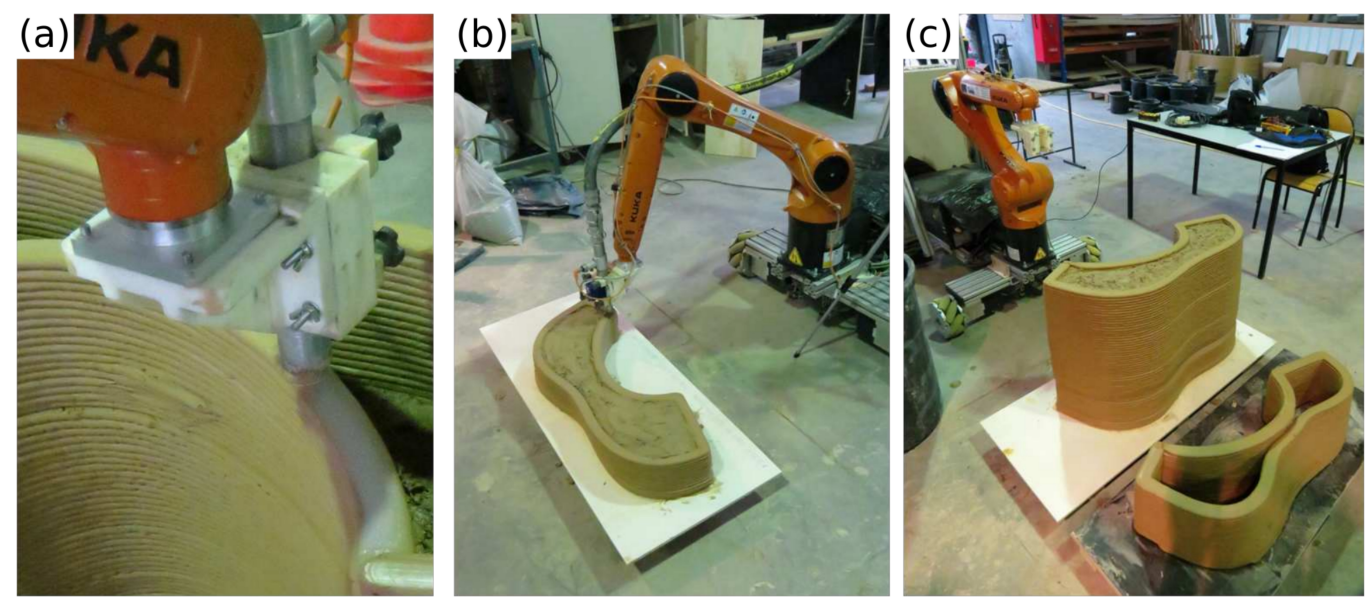

Fig. 10. Complex geometric shape printed a) zoom on the nozzle b) robot in the printing phase c) finished shapes with and without filling by foam composite

final height fixed in the CAD file.

In a building site, the robot could include two printing devices, one for the structural material and another for the insulating material. 


\section{Table 3}

Measurements at fresh state

\begin{tabular}{|c|c|c|c|c|}
\hline \multirow[t]{2}{*}{ Mixes } & \multicolumn{2}{|l|}{ Spread diameter* } & \multirow{2}{*}{$\begin{array}{c}\text { Time }{ }^{* * *} \\
(\min )\end{array}$} & \multirow{2}{*}{$\begin{array}{l}\mathrm{T}_{\text {Vicat }} \\
(\mathrm{min})\end{array}$} \\
\hline & Mean value $(\mathrm{mm})$ & $\mathrm{SD}^{* *}$ & & \\
\hline G0 & 119 & 1.3 & 8.9 & 9.5 \\
\hline G1 & 183 & 5.4 & 18 & 29.5 \\
\hline G2 & 176 & 2.1 & 15 & 20 \\
\hline G3 & 95 & 1.6 & 5 & - \\
\hline G-QF0 & 157 & 4.4 & 18 & 15.5 \\
\hline G-QF1 & 188 & 1.7 & 19.8 & 23.5 \\
\hline $\mathrm{G}-\mathrm{QF} 2$ & 199 & 4.6 & $\mathrm{NTV}^{* * * *}$ & - \\
\hline G-QF2' & 192 & 1.2 & 17 & 20 \\
\hline G-QF3 & 108 & 2.9 & 5 & - \\
\hline $\mathrm{PC} 0$ & 155 & 0.5 & 8.7 & 7.6 \\
\hline $\mathrm{PC} 1$ & 179 & 0.7 & 8.7 & 16.9 \\
\hline $\mathrm{PC} 2$ & 192 & 7.7 & 13.4 & 14 \\
\hline $\mathrm{PC} 3$ & 123 & 3.1 & 9.3 & - \\
\hline PC-QF0 & 146 & 0.7 & 18.6 & 13.5 \\
\hline PC-QF1 & 177 & 10.2 & 17.6 & 32.5 \\
\hline PC-QF2 & 173 & 1.4 & $\mathrm{NTV}^{* * * *}$ & - \\
\hline PC-QF2' & 186 & 0.7 & 8.8 & 33 \\
\hline PC-QF3 & 135 & 1.2 & 9 & - \\
\hline
\end{tabular}

* five minutes after the incorporation of water

** standard deviation

${ }^{* * *}$ corresponding to a spread diameter of $100 \pm 10 \mathrm{~mm}$

${ }^{* * * *}$ no targeted value after $120 \mathrm{~min}$ 


\section{Table 4}

Evolution of the dry densities according to the studied mixes

\begin{tabular}{ccc} 
Designation & $\begin{array}{c}\text { Dry density } \\
\mathrm{kg} \cdot \mathrm{m}^{-3}\end{array}$ & $\begin{array}{c}\text { Percentage change } \\
\text { G0 }\end{array}$ \\
G1 & 577.6 & - \\
G2 & 516.6 & 31.2 \\
G3 & 483.6 & 33.5 \\
G-QF0 & 786.5 & 37.8 \\
G-QF1 & 586.3 & - \\
G-QF2 & 582.7 & 25.8 \\
G-QF3 & 390.4 & 26.2 \\
\hline PC0 & 878.3 & 51 \\
PC1 & 728.3 & - \\
PC2 & 635.3 & 19.3 \\
PC3 & 433.4 & 31.3 \\
\hline PC-QF0 & 840 & 57.2 \\
PC-QF1 & 662.7 & - \\
PC-QF2 & 654.7 & 22.8 \\
PC-QF3 & 386.9 & 58.3 \\
\hline
\end{tabular}




\section{Table 5}

Mass proportions of components per cubic meter of each mix

\begin{tabular}{|c|c|c|c|c|c|c|c|}
\hline Mixes & Gypsum & $\begin{array}{l}\text { Prompt } \\
\text { Cement } \\
(\mathrm{kg})\end{array}$ & $\begin{array}{c}\text { Quarry } \\
\text { Fines } \\
\text { (kg) }\end{array}$ & $\begin{array}{c}\text { Flax } \\
\text { shives } \\
(\mathrm{kg})\end{array}$ & Water & $\begin{array}{c}\text { Foaming } \\
\text { agent } \\
(\mathrm{kg})\end{array}$ & DGPCI* \\
\hline G0 & 706.9 & 0 & 0 & 70.7 & 565.5 & 0 & \\
\hline G1 & 483.4 & 0 & 0 & 48.3 & 386.7 & 3.38 & 31.6 \\
\hline G2 & 462.9 & 0 & 0 & 46.3 & 370.3 & 7.41 & 34.5 \\
\hline G3 & 400.7 & 0 & 0 & 80.1 & 320.6 & 2.81 & 43.3 \\
\hline G-QF0 & 357.5 & 0 & 357.5 & 71.5 & 572 & 0 & 49.4 \\
\hline G-QF1 & 264.8 & 0 & 264.8 & 53 & 423.7 & 3.71 & 62.5 \\
\hline G-QF2' & 394.8 & 0 & 131.6 & 52.6 & 421.1 & 3.69 & 44.2 \\
\hline G-QF3 & 161.7 & 0 & 161.7 & 64.7 & 258.8 & 2.26 & 77.1 \\
\hline $\mathrm{PC} 0$ & 0 & 798.5 & 0 & 79.8 & 638.8 & 0 & \\
\hline PC1 & 0 & 657.9 & 0 & 65.8 & 526.3 & 4.61 & 17.6 \\
\hline $\mathrm{PC} 2$ & 0 & 569.3 & 0 & 56.9 & 455.4 & 9.11 & 28.7 \\
\hline PC3 & 0 & 359.1 & 0 & 71.8 & 287.3 & 2.51 & 55 \\
\hline PC-QF0 & 0 & 381.8 & 381.8 & 76.4 & 610.9 & 0 & 52.2 \\
\hline PC-QF1 & 0 & 299.3 & 299.3 & 59.9 & 478.9 & 4.2 & 62.5 \\
\hline PC- & 0 & 443.6 & 147.9 & 59.1 & 473.1 & 4.14 & 44.4 \\
\hline \multicolumn{8}{|l|}{ QF2' } \\
\hline PC-QF3 & 0 & 160.3 & 160.3 & 64.1 & 256.4 & 2.24 & 79.9 \\
\hline
\end{tabular}

*Decreasing of Gypsum or Prompt Cement Incorporation 


\section{Table 6}

Thermophysical properties of developed mixes

\begin{tabular}{lcccc}
\hline Material & $\begin{array}{c}\lambda \\
\left(\mathrm{W} \cdot \mathrm{m}^{-1} \cdot \mathrm{K}^{-1}\right)\end{array}$ & $\begin{array}{c}\rho \\
\left(\mathrm{kg} \cdot \mathrm{m}^{3}\right)\end{array}$ & $\begin{array}{c}C_{p} \\
\left(\mathrm{~J} \cdot \mathrm{kg}^{-1} \cdot \mathrm{K}^{-1}\right)\end{array}$ & $\begin{array}{c}\mathrm{W}^{*} \\
(\%)\end{array}$ \\
\hline G0 & 0.14 & 826 & 1519 & 2.3 \\
G1 & 0.125 & 609 & 1452 & 0.9 \\
G2 & 0.104 & 562 & 1424 & 4.4 \\
G3 & 0.107 & 526 & 1412 & 0.8 \\
\hline PC0 & 0.16 & 910 & 1347 & 8.5 \\
PC1 & 0.135 & 734 & 1316 & 9.4 \\
PC3 & 0.095 & 451 & 1577 & 4.4 \\
\hline G-QF0 & 0.158 & 797 & 1384 & 2.6 \\
G-QF1 & 0.123 & 600 & 1194 & 2.4 \\
G-QF3 & 0.093 & 371 & 1407 & 2.3 \\
\hline PC-QF0 & 0.138 & 861 & 1290 & 6.0 \\
PC-QF1 & 0.085 & 540 & 1597 & 2.1 \\
\hline Hemp earth block [15] & 0.21 & 1100 & 886 & 0 \\
Autoclaved aerated concrete block [31] & 0.083 & 367 & $1160-1450$ & - \\
\hline
\end{tabular}

${ }^{*}$ Water content 


\section{Conclusion}

This research work aimed to develop a flax shive-based rapid hardening lightweight composite for the insulation of structures built by $3 \mathrm{D}$ printing. Eighteen mixes, containing flax shives, gypsum or prompt cement, quarry fines and foaming agent, have been studied in their fresh and hardened states. Among these eighteen mixes, four mixes have been considered as references. The others mixes were either without foaming agent, or with a higher proportion of foaming agent, or with a higher proportion of flax shives, or with various proportions of quarry fines in substitution of gypsum or prompt cement. The study at fresh state was based on the flow table test and the Vicat test to determine the water content of the four reference mixes for a satisfying flowability in order to compare the flowability levels of the others mixes and to follow the kinetics of hardening. These tests show that the foaming agent gives a higher flowability and slows the hardening process. With a high proportion of flax shives, the Vicat test is not adapted due to the open structure of the materials. With an excessive proportion of quarry fines in substitution of hydraulic binder, the mix is not resistant enough and no hardening can be observed. For twelve mixes, the hardening starts between 7 and 33 minutes from the water is incorporated in the mixer. After the curing period, the dry densities of the samples were calculated from their dimensions and weights before and after oven drying. Overall, regarding the mixes, the dry densities vary from $386.9 \mathrm{~kg} \cdot \mathrm{m}^{-3}$ up to $878.3 \mathrm{~kg} \cdot \mathrm{m}^{-3}$ depending on the presence of foaming agent and on the proportion of flax shives, which have their own natural porosity. The presence of foaming agent induces air voids in the form of spherical bubbles of various sizes, which is very beneficial to 
the acoustic absorption and thermal properties of these mixes. In addition, the substitution of gypsum or prompt cement by quarry fines, the decrease in hydraulic binder incorporation can be up to $79.9 \%$. On the mechanical side, the strengths of mixes are low. The comparison of various curing periods shows that the compressive strengths increase according time. At 28 days, the compressive strengths of mixes with foaming agents can reach up to $0.908 \mathrm{MPa}$. Gypsum delivers the best mechanical performances. The setting of prompt cement seems altered due, probably, to the release of sugar by the flax shives when in contact with water.

In association with a structural part, as in wooden construction, the developed mixes can suit 3D printing thanks to their good workability at short notice, their rapid hardening and their sufficient strength to resist to their own load. With their stiff state, the mixes could represent an interesting alternative to flexible insulating materials such as glass wool, which may settle over time and decrease the thermal performances of the wall. The mixes developed in this paper have great potential as thermal insulators and can improve the acoustic performances of a building. The microstructures present in the mixes and especially those with a low density require new investigations to better understand the link between the developed porosity (sizes of pores, repartition of pores, connected volume, global volume) and the measured performances. New researches will be done to improve mechanical strengths, in particular by treating flax shives before mixing with the others components, to limit water absorption and release of hydrosoluble molecules harmful for formation of hydrates.

By using a double device of printing, a bearing wall with high acoustic and 
thermal performances could be built by printing both a flax shive-based lightweight composite and a structural material (e.g. cementitious concrete or clayey concrete).

3. Feng P, Meng X, Chen JF, Ye L. Mechanical properties of structures 3d printed with cementitious powders. Construction and Building Materials 2015;93(Supplement C):486 - 497. doi: https://doi.org/10.1016/j.conbuildmat.2015.05.132. 
4. Khalil N, Aouad G, Cheikh KE, Rémond S. Use of calcium sulfoaluminate cements for setting control of 3d-printing mortars. Construction and Building Materials 2017;157(Supplement C):382 - 391. doi: https://doi.org/10.1016/j.conbuildmat.2017.09.109.

5. Panda B, Paul SC, Tan MJ. Anisotropic mechanical performance of $3 \mathrm{~d}$ printed fiber reinforced sustainable construction material. Materials Letters 2017;209(Supplement C):146 - 149. doi: https://doi.org/10.1016/j.matlet.2017.07.123.

6. Chen B, Liu N. A novel lightweight concrete-fabrication and its thermal and mechanical properties. Construction and Building Materials 2013;44:691 - 698 .

7. Hanif A, Diao S, Lu Z, Fan T, Li Z. Green lightweight cementitious composite incorporating aerogels and fly ash cenospheres - mechanical and thermal insulating properties. Construction and Building Materials 2016;116(Supplement C):422 - 430. doi: https://doi.org/10.1016/j.conbuildmat.2016.04.134.

8. Liu W, Apel D, Bindiganavile V. Thermal properties of lightweight dry-mix shotcrete containing expanded perlite aggregate. Cement and Concrete Composites 2014;53:44 - 51 .

9. Horpibulsuk S, Suddeepong A, Chinkulkijniwat A, Liu MD. Strength and compressibility of lightweight cemented clays. Applied Clay Science $2012 ; 69: 11-21$. 
16. Vercelheze AE, Fakhouri FM, Dall'Antônia LH, Urbano A, Youssef EY, Yamashita F, Mali S. Properties of baked foams based on cassava starch, 
sugarcane bagasse fibers and montmorillonite. Carbohydrate Polymers 2012;87(2):1302 - 1310 .

17. Khazma M, Goullieux A, Dheilly RM, Rougier A, Quéneudec M. Optimization of flax shive-cementitious composites: Impact of different aggregate treatments using linseed oil. Industrial Crops and Products 2014;61(Supplement C):442 - 452. doi: https://doi.org/10.1016/j.indcrop.2014.07.041.

18. Russel P. 3-d printed earthen architecture. Tech. Rep.; Aston University; 2015 .

19. AFNOR . Soil : inverstigation and testing. determination of atterberg's limits. liquid limit test using cassagrande apparatus. plastic limit test on rolled thread. NF P 94-051; 1993.

20. AFNOR . Methods of test for mortar for masonry - part 3 : determination of consistence of fresh mortar (by flow table). NF EN 1015-3; 1999.

21. AFNOR . Admixtures for concrete, mortar and grout - test methods part 2 : determination of setting time. NF EN 480-2; 2006.

22. Arnaud L, Gourlay E. Experimental study of parameters influencing mechanical properties of hemp concretes. Construction and Building Materials 2012;28:50-56. doi:10.1016/j.conbuildmat.2011.07.052. ISSN 0950-0618.

23. ASTM . Standard test method for measurement of normal incidence 
sound transmission of acoustical materials based on the transfer matrix method. E 2611-09; 2009.

24. AFNOR . Thermal performance of building materials and products determination of thermal resistance by means of guarded hot plate and heat flow meter methods - dry and moist products of medium and low thermal resistance. NF EN 12664; 2001.

25. Rahim M, Douzane O, Le AT, Promis G, Laidoudi B, Crigny A, Dupre B, Langlet T. Characterization of flax lime and hemp lime concretes: hygric properties and moisture buffer capacity. Energy and Buildings $2015 ; 88: 91-99$.

26. Belayachi N, Hoxha D, Slaimia M. Impact of accelerated climatic aging on the behavior of gypsum plaster-straw material for building thermal insulation. Construction and Building Materials 2016;125(Supplement C):912 - 918. doi:https://doi.org/10.1016/j.conbuildmat.2016.08.120.

27. Glé P, Gourdon E, Arnaud L. Acoustical properties of materials made of vegetable particles with several scales of porosity. Applied Acoustics $2011 ; 72(5): 249-259$.

28. Marincic I, Ochoa J, Alpuche M, Gonzalez I. Comparative analysis of the thermal behavior between cellular concrete blocks and stabilized earth blocks as wall materials. Energy Procedia 2014;57:1783-1791.

29. Maillet D, André S, Batsale J, Degiovanni A, Moyne C. Thermal Quadrupoles. Solving the Heat Equation through Integral Transforms. 2000. 
30. Jin X, Zhang X, Gao Y, Wang G. Thermal performance evaluation of the wall using heat flux time lag and decrement factor. Energy and Buildings 2012;47:369-374.

31. Koci V, Madera J, Cerny R. Computer aided design of interior thermal insulation system suitable for autoclaved aerated concrete structures. Applied Thermal Engineering 2013;58:165-172. 